\title{
Algunos problemas de derecho internacional planteados por la nacionalización de la industria del cobre en Chile*
}

\begin{abstract}
FrANGISGO ORREGo VIGU $\widetilde{N} A$, Abogado Chileno, es miembro del Instituto Interamericano de Estudios Jurídicos Internacionales y desde 1965 Asesor Especial del Departamento de Asuntos Jurídicos de la OEA. Es autor de La Integración Politica (1966); Developments in the Latin America Free Trade Association (1967) y de una publicación reciente sobre Derechos del Mar. Es coautor de Derecho de la Integración Latinoamericana (1969).
\end{abstract}

El complejo proceso de la nacionalización de la industria del cobre en Chile, ha planteado numerosos interrogantes de importancia y suscitado puntos de vista encontrados acerca de los principios y normas del derecho internacional aplicables a la afectación de propiedad, intereses y derechos de extranjeros. El propósito de este artículo es examinar de una manera objetiva algunos de estos problemas y puntos de vista, con particular referencia a los precedentes bien establecidos y a las doctrinas contemporáneas del derecho internacional en esta problemática materia. Este ensayo de objetividad ciertamente no es una tarea fácil, pues la nacionalización realizada por Chile necesariamente involucra conceptos discrepantes acerca del derecho de propiedad y su protección bajo el derecho nacional e internacional.

Las exigencias del derecho internacional en materia de afectación de propiedad, sólo fueron tomadas en cuenta subsidiariamente durante el proceso de reforma constitucional que dio origen a la nacionalización de la industria del cobre ${ }^{1}$. Sin embargo, durante el de-

*Este estudio fue originalmente publicado en inglés por The American Journal of International Law, Vol. 67, No 4, October 1973 (Traducción del Autor).

${ }^{2}$ E1 Mensaje del Ejecutivo del 21 de diciembre de 1970 por el cual se propuso la reforma constitucional, expresaba que la nacionalización es "un derecho reconocido por la Carta de las Naciones Unidas" e "incluso por la Corte Suprema de los Estados Unidos". Senado, Boletin NQ 25.073: Anexo al Informe de la Comisión de Constitución, 17 de enero de 1971, p. 15. De acuerdo con lo que fue posteriormente declarado por los representantes del Ejecutivo en la Comisión del 
bate parlamentario constantemente se destacó que la Resolución 1803 (XVII) de la Asamblea General de las Naciones Unidas, del 14 de diciembre de $1962^{2}$, proporcionaba una legítima y fundamental base de derecho internacional para la nacionalización. Aun cuando no es del caso reexaminar la historia legislativa de esta resolución, ciertamente es importante clarificar los conceptos básicos en que ella se inspira, particularmente por haber sido Chile uno de sus más activos promotores en las Naciones. Unidas. ${ }^{3}$

Desde la aprobación de la Resolución 1314 (XIII) de la Asamblea. General, del 12 de diciembre de 1958, quedó claro que en la afectación de propiedad de extranjeros debían tenerse "debidamente en cuenta los derechos y deberes de los Estados en virtud del derecho internacional". Este concepto también fue incorporado en el Convenio de las Naciones Unidas sobre Derechos Económicos, Sociales y Culturales y, significativamente, en la propia Resolución 1803. De ahí que pueda sostenerse que los principios, derechos y obligaciones establecidos por la Resolución 1803 se encuentran incorporados en otros principios relevantes del derecho internacional y gobernados por éstos. De esta manera, la Resolución no solamente

Senado, dichas referencias eran a Ia Resolución I803 (XVII) y al caso Sabbatino. Boletin cit., pp. 34, 93. La Resolución 1803 (XVII) fue invocada virtualmente en todas las sesiones de la Comisión y del Senado, y fue reproducida in extenso en los documentos oficiales en dos oportunidades. Si bien la Comisión del Senado consultó regularmente a profesores y expertos en derecho minero $y$ constitucional, este no fue el caso con los profesores de derecho internacional. El punto de vista del derecho internacional fue hecho presente por profesores universitarios en artículos publicados en el Diario El Mercurio del 5 y is de febrero $y$ del 20 de abril de 1971.

2Además de las menciones a la Resolución hechas en la tramitación de la reforma constitucional, ésta ha sido invocada por muchos otros instrumentos $y$ declaraciones. Véase, por ejemplo, el artículo decimoséptimo transitorio de la Constitución, que se refiere al "ejercicio del derecho soberano e inalienable del Estado a disponer libremente de sus riquezas y recursos naturales"; y el Decreto No 92 del 28 de septiembre de 1971 sobre rebaja de utilidades excesivas. Véase también el Discurso pronunciado por el Subsecretario de Relaciones Exteriores de Chile en el segundo período ordinario de sesiones de la Asamblea General de Ia OEA; Doc. OEA/AG C-136-72, 14 de abril de 1972.

${ }^{3} \mathrm{La}$ Resolución 1803 (XVII) se originó en las recomendaciones de la Comisión de la Soberanía Permanente sobre los Recursos Naturales, creada por la Resolución 1314 (XIII) del 12 de diciembre de 1958. Estas recomendaciones fueron propuestas por un proyecto de Resolución presentado por la delegación de Chile. Véase Karol N. Gess: "Permanent Sovereignty over natural resources", 13, International and Comparative Law Quarterly', April 1964, p. 407. Véase también Daniel Schwetzer: "Debate en el Senado sobre soberania y recursos naturales", El Mercurio, 26 de enero de 1971, p. 3. Véase también Stephen M. Schwebel: "Story of the U.N.'s Declaration on Permanent Sovereignty over Natural Resources", 49, American Bar Association Joumal, p. 463, 1963. 
es consistente con los principios generalmente reconocidos del derecho internacional, sino que además es declaratoria de los mismos ${ }^{4}$. Por lo demás, esta es la única forma realista de poder interpretar el verdadero significado y alcance de la' resolución.

Debe observarse que tradicionalmente Chile ha reconocido la aplicabilidad del derecho internacional a las situaciones que afectan los derechos de los extranjeros ${ }^{5}$. Como to expresara el delegado de Chile, la Resolución 1803 "no proponía modificaciones a los principios de derecho internacional existentes y, en el hecho, en dos lugares

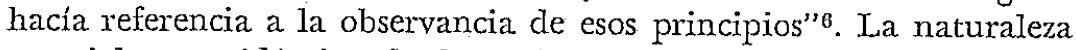
esencialmente idéntica de los principios enunciados en esta resolución y de aquellos bien establecidos en el derecho internacional, es particularmente significativa si se tiene presente que, durante la elaboración de la resolución, la Comisión de Derecho Internacional y la comunidad académica se encontraban debatiendo sobre los problemas de política substantiva relativos a los principios de derecho internacional que rigen la responsabilidad del Estado. ${ }^{7}$

EL DEREGHO A NAGIONALIZAR Y LA PROTEGGIÓN INTERNAGIONAL DE LOS DERECHOS ADQUIRIDOS POR EXTRANJEROS

El derecho del Estado a nacionalizar la propiedad de extranjeros ya no es discutido seriamente. Tanto el gobierno de Chile como el de Estados Unidos han admitido y reconocido este derecho ${ }^{8}$. Sin

"Véase en generaI O. Y. Asamoah: The Legal Significance of the Declarations of the General Assembly of the United Nations, Nijhoff, 1966.

Véase el Discurso del Subsecretario de Relaciones Exteriores, cit. Nota 2 supra. También, Intervención del Ministro de Relaciones Exteriores en la sesión de la Cámara de Diputados del 2 de agosto de 1972, La Nación, 6 de agosto de 1972.

'Naciones Unidas. Doc A/G.2/SR. 842, p. 12 y A/C.2/SR. 834, p. 19.

'F. V. Garcia Amador: "Proyecto revisado sobre la responsabilidad internacional del Estado por daños causados en su territorio a la persona o propiedad de extranjeros", Doc. A/CN.4/34.Add. I, II de diciembre de 1961. Anuario de la Comisión de Derecho Internacional, Vol. II, 1961. Sohn and Baxter: "Draft Convention on the International Responsability of State for Injuries to Aliens", Draft, $N^{\circ} 12$, I5 de abril de 1961, 55, American Journal of International Law, $548,1961$.

${ }^{8}$ Declaración del señor Charles A. Meyer ante el Subcomité de Asuntos Interamericanos del Comité de Asuntos Internacionales de la Cámara de Representantes, 13 de octubre de 1971. Department of State Bulletin, Vol. 60, 1971, p. 498. 
embargo, el derecho internacional, según se encuentra expresado en la Resolución 1803 y en las decisiones de tribunales internacionales, ha impuesto algunas limitaciones al ejercicio de los poderes expropiatorios del Estado cuando afectan los intereses y derechos de los extranjeros ${ }^{\theta}$. Se hace necesario, por tanto, examinar hasta qué punto el derecho internacional exige al Iistado respetar los derechos adquiridos de. extranjeros y garantizar su protección.

Los tribunales internacionales han consagrado desde hace tiempo la obligación que tiene el Estado de respetar los derechos adquiridos por extranjeros, como una norma general del derecho internacional ${ }^{10}$. La Resolución 1803 descansa en parte en este principio, según lo evidencia su historia legislativaxi y la opinión de los principales autores que se han preocupado de su estudio ${ }^{12}$. Sin embargo, este principio no es absoluto ni inmutable, pues el derecho internacional reconoce la función social de la propiedad, como lo expresa la Resolución 1803. Inequívocamente la Resolución declara que, en cuanto a la afectación de la propiedad, la utilidad pública, seguridad o interés nacional son superiores al mero interés individual o privado, tanto nacional como extranjero ${ }^{13}$. Aquellos que cri-

Véase también, Meyer: Respuesta de la Delegación de Estados Unidos a las exposiciones de los delegados del Ecuador y Chile, Doc OEA/AG/C-143/72, 15 de abril de 1972.

'Para un examen de las decisiones de los tribunales internacionales en este punto, véase F. V. García Amador: Principios de Derecho Internacional que rigen la responsabilidad, Madrid, 1963, pp. 306-310.

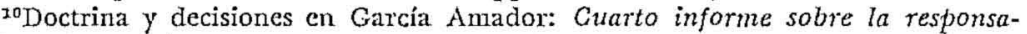
bilidad internacional. Anuario de la Comisión de Derecho Internacional, Vol. II, 1959, p. 4. Véase también el arbitraje en el caso Aramco; Whiteman: Digest of International Latu, Vol. 8, 1967, p. 912.

${ }^{11}$ Algunos países recién accedidos a la independencia propusieron que sólo debían respetarse los derechos adquiridos con posterioridad a la independencia, pero no aquellos adquiridos bajo el dominio colonial. Naciones Unidas, Doc. A/C.2/SR. 846, p. 7; A/C.2/SR. 851, pp. 6-7. El párrafo preambular No 5 se introdujo para atender este aspecto. Resulta on consecuencia que los derechos adquiridos en un Estado independiente están claramente protegidos por Ia Resolución. La delegación de Chile concordó desde el punto de vista jurídico con la posición de Holanda, que favorecía la protección de los derechos adquiridos en cualquier circunstancia, pero sugirió no incorporar disposiciones de detalle. Naciones Unidas, Doc. A/AC.97/SR.28, p. 5. Aun cuando el Presidente Allende ha declarado que "la explotación norteamericana del cobre es un verdadero enclave colonial en la cconomía chilena", la situación es dificilmente comparable. Senado, Boletín cit., Nota 1 supra, p. 6.

${ }^{12}$ Asamoah, op. cit., Nota 4 supra, p. 99; Gess, loc. cit., Nota 3 supra, p. 443; García Amador, op. cit., Nota 9 supra, p. 201; Schwebel, loc. cit., Nota 3 supra, p. 468.

${ }^{13}$ Esta posición ya se encuentra en decisiones internacionales a partir de 1930. Véase Garcia Amador, Cuarto Informe cit., Nota 10 supra, p. 5. 
tican el principio ${ }^{14}$ se fundamentan en una visión superada del derecho internacional y su capacidad de evolución, en función del cambio global de circunstancias.

Desde el momento en que este principio no es absoluto, el Estado puede adoptar medidas que afecten los derechos adquiridos de extranjeros, en la medida en que ellas no sean incompatibles con las exigencias del derecho internacional o se adopten en violación de un tratado. En relación a la nacionalización del cobre, tal tratado no existía entre Chile y los Estados Unidos. ${ }^{15}$

El debate del Senado sobre la reforma constitucional se refirió con considerable detalle a los problemas relativos a los derechos adquiridos por las compañías del cobre bajo los acuerdos alcanzados con el gobierno del Presidente Frei ${ }^{x}$. Si bien muchos de los argumentos se refirieron a aspectos del derecho nacional, también se mencionaron principios relevantes de derecho internacional. En particular, se formularon fuertes críticas a una de las reformas propuestas, por la cual un particular afectado en sus derechos no podria "invocar beneficios, franquicias, liberaciones o garantías que emanen de acuerdos, convenios, convenciones o contratos celebrados por el Estado o con sus autoridades, aun cuando hayan sido otorgados en cumplimiento o con sujeción a leyes anteriores a las medidas adoptadas, o hayan sido aprobados por dichas leyes"17. Se indicó que una disposición de esta naturaleza no sólo violaría los derechos adquiridos sino también demostraría la irresponsabilidad del Estado y tendría repercusiones adversas a través de la comunidad internacional. Además se indicó que tal disposición sería inconsistente con el significado y la buena fe exigida implícitamente por la. Resolución 180318. En un momento dado, el representante del Ejecutivo justificó la propuesta sobre la base de que solamente

1s Para un examen de esta crítica, Ibid., pp. 5-7, citando particularmente a S. Friedman: Expropiation in International Law, 1953, p. 126, y Kaeckenbeeck: "La Protection Internationale des Droits Acquis", Recueil des Cours de l'Académie de Droit International, Vol. 59, 1937, p. 361.

${ }^{15} \mathrm{Si}$ bien tanto Ghile como Estados Unidos suscribieron el Convenio Económico de Bogotá de 1948, que impone condiciones estrictas en lo relativo a la propiedad de extranjeros, ninguno de los clos paises lo ratificó. El diferente enfoque de los países latinoamericanos y de los Estados Unidos en torno a este problema, ya quedó en evidencia durante la discusión del Convenio. Whiteman, Digest of International Law, Vol. 8, 1967, pp. 1091-92.

10Para los textos de los acuerdos y otros materiales, International Legal Materials, Vol. 6, 1967, pp. 424-453, 454-465, 1146-1I61; Vol. 8, 1969, pp. 1073-1078; y Vol. 9, 1970, pp. 921-974.

${ }^{27}$ Artículo $10^{\circ}$ c) del proyecto de reforma constitucional propuesto por el Ejecutivo. Senado, Boletín cit., Nota I supra, p. 16.

${ }^{18}$ Senado, Boletín cit., Nota 1 supra, pp. 110-112, 123-124, 132, 141. 
se refería a aquellos casos en que el derecho del particular no había sido lícitamente adquirido. ${ }^{19}$

Este debate es significativo por cuanto revela que el legislador tuvo presente la eventual responsabilidad en que puede incurrir el Estado si las medidas adoptadas para la afectación de derechos adquiridos no observaban las condiciones requeridas por el derecho internacional. La eventual aplicación de sanciones internacionales y la situación inconfortable que podría surgir fueron también mencionadas, así como que en cualquier caso tal medida violaría el orden moral internacional.20

\section{II}

LOS MOTIVOS Y PROPÓSITOS DE LA NAGTONALIZAGIÓN

Reconocido el derecho del Estado a afectar derechos adquiridos, cabe preguntarse en qué medida la nacionalización de la industria del cobre se conformó a las condiciones exigidas por el derecho internacional. En primer lugar, la nacionalización se basó en una clara y legítima determinación de necesidad pública como lo exige la Resolución 1803. Más todavía, ella fue debidamente autorizada a través de los procedimientos normales de reforma constitucional y gozó del apoyo tanto del poder Ejecutivo como del poder Legislativo. Consecuentemente, la procedencia y validez de la nacionalización como tal, no puede ser objetada a la luz de los principios aplicables del derecho internacional. Sin embargo, cuando se encuentran involucrados los derechos de extranjeros, el derecho internacional impone ciertas limitaciones al ejercicio de los poderes del Estado. Una premisa básica es, desde luego, que la afectación de propiedad no sea arbitraria o discriminatoria. Aun cuando no es fácil de definir en términos de categorias jurídicas, el concepto de arbitrariedad involucra un profundo juicio moral acerca de lo que es justo e injusto, preocupación que se ha manifestado incluso en el derecho relativo a la protección internacional de los derechos humanos ${ }^{21}$. Esta dimensión moral del concepto de arbitrariedad se encuentra intimamente ligada al concepto del enriquecimiento in-

19Ibid., p. 124. Es posible decucir de esta declaración que cuando el derecho ha sido licitamente adquirido, debe ser respetado.

20Ibid., p. 112.

${ }^{21}$ Declaración Universal de los derechos humanos, aprobada por la Asamblea General de las Naciones Unidas el 10 de diciembre de 1948, Artículo 17, 2. 
debido, principio general del derecho reconocido por las naciones civilizadas $^{22}$ que prohíbe a la comunidad beneficiarse indebidamente a expensas de los particulares' ${ }^{23}$ y que ha sido sugerido como la base fundamental en que descansa la obligación de indemnizar²4. Por otra parte, también estrechamente ligado a la arbitrariedad se encuentra el concepto del abuso del derecho ${ }^{25}$, que tiene por objeto evitar que el Estado ejerza sus poderes de manera de evadir obligaciones internacionales que no han sido definidas con precisión, o de actuar de cualquier manera que sea contraria al significado e intención última del ordenamiento jurídico internacional. El derecho internacional ha desarrollado criterios específicos para juzgar si acaso las acciones de los Estados son arbitrarias, criterios que se refieren principalmente a los motivos y propósitos del acto de afectación, denegación de justicia, discriminación y; sobre todo, la indemnización.

EL PUNTO DE VISTA DE LA DENEGACIÓN DE JUSTICIA

Otro aspecto crítico que se da en las situaciones de nacionalización es si acaso los recursos internos de que disponen los extranjeros cuya propiedad. ha sido afectada, son adecuados en términos de criterios nacionales e internacionales. Con la intención de minimizar las prácticas abusivas y arbitrarias, el derecho internacional obliga al Estado a proporcionar a los extranjeros mecanismos judiciales o administrativos efectivos para la solución de las controversias a que den origen las medidas de afectación. Si acaso hay retardo injustificado en la administración de justicia, graves irregularidades procesales, decisiones manifiestamente injustas o inejecución de sentencias en casos que involucren a los extranjeros, el Estado puede ser responsabilizado por actos de denegación de justicia ${ }^{26}$. Otro p. 196.

${ }^{22}$ Wolgang Friedmann: The Changing Structure of International Law, 1964, ${ }^{196} \mathrm{~F}$.

${ }^{2}$ Ibid.; también citando a Cheng: General Principles of Law as Applied by International Gourts and Tribunals, 1953, p. 48. Véase también Friedmann: "Social Conflict and the Protection of Foreign Investment", Procedings of the American Society of International Law, 1963, pp. 131-132.

${ }^{25} \mathrm{~F}$. V. García Amador, Cuarto informe cit., Nota 10 supra, p. 15.

${ }^{28}$ Garcia Amador, Segundo informe sobre la responsabilidad internacional, Anuario de la Comisión de Derecho Internacional, Vol. II, 1957, pp. 110-112. 
aspecto relacionado es la composición de los órganos judiciales o administrativos que tienen jurisdicción sobre tales controversias, así como el acceso a los mismos.

A este respecto, la imparcialidad e independencia del Tribunal Especial del Cobre, establecido para conocer de los reclamos resultantes de la nacionalización del cobre, han sido objetadas con motivo de su composición. El proyecto original del Ejecutivo fue concebido de tal manera que su propio punto de vista sería compartido por la mayoría de los miembros del Tribunal. De acuerdo a ese proyecto, el Tribunal estaría compuesto por tres funcionarios gubernamentales y dos magistrados, uno de la Corte Suprema y el otro del Tribunal Constitucional, este último también designado por el Presidente de la República ${ }^{27}$. Esta proposición fue posteriormente modificada por el Congreso y el Tribunal, según quedó constituido, incluyó dos funcionarios gubernamentales y tres magistrados, uno de cada uno de los órganos que se mencionaron y el otro de la Corte de Apelaciones de Santiago; además, los magistrados fueron designados por sus respectivos órganos ${ }^{28}$. Esta modificación no cambió la mayoría en el Tribunal del Cobre, puesto que el Tribunal Constitucional, la mayoría de cuyos miembros apoyaban al Ejecutivo, elegía su propio representante ante el Tribunal del Cobre. Independientemente del procedimiento para su selección, el Tribunal del Cobre, según fue constituido, no podría ser considerado contrario a los requisitos del derecho internacional. Más todavía, aquellos argumentos que sugieren que la exclusión del Poder Judicial del conocimiento de las controversias que surjan de la nacionalización ${ }^{29}$, constituye un acto contrario al derecho internacional, deben ser descartados igualmente.

Como lo expresa García Amador:

${ }^{27}$ Proyecto de reforma constitucional cit., Nota I supra, p. 435.

${ }^{28}$ Artículo transitorio 17 (c) de la Constitución; según reformado.

${ }^{20} \mathrm{La}$ exclusión del Poder Judicial del conocimiento de cualquier asunto resultante de la nacionalización del cobre fue oficialmente propuesta por el Ejecutivo sobre la base de que la Corte aplicaría "un criterio que degrada el asunto, reduciendo todá la materia a una mera relación entre personas privadas gobernada por el derecho privado". Véase Stern: "The Judicial and Administrative Procedures Involved in The Chilean Copper Expropriations", Proceedings of the American Society of International Law, 1972, pp. 205-213. También Senado, Boletín cit., Nota 1 supra, p. 38. Para los efectos de la reforma agraria, que Iepresenta otra gran área en que se ha llevado a la práctica la legislación expropiatoria, también se establecieron tribunales especiales para resolver las controversias. Sobre estos procedimientos, véase Goldman and Paxman: "Real Property Valuations in Argentina, Chile, and Mexico". En R. Lillich (ed.): The Valuation of Nationalized Property in International Law, Vol. II, 1973, pp. 142-144. 
"Incluso pudiera pensarse en el derecho del Estado a apartarse cuando circunstancias especiales lo requieran y justifiquen, de los métodos y procedimientos ordinarios, siempre que con ello no se discrimine injustificadamente en perjuicio de los extranjeros o no se incurra en algún otro acto u omisión contrario al derecho internacional". ${ }^{30}$

Sin embargo, el aspecto más delicado que ha surgido de la nacionalización, se refiere a la decisión del Tribunal del Cobre declarando inadmisibles las apelaciones presentadas por las compañías del cobre americanas en contra del decreto del Presidente que ordenó las rebajas por utilidades excesivas ${ }^{31}$. El Ejecutivo tomó la posición de que el Tribunal carecía de jurisdicción para conocer de esas rebajas, pues ellas constituían actos de gobierno que pertenecían a los poderes exclusivos del Presidente y a su discrecionalidad. Las compañías americanas naturalmente sostuvieron el punto de vista opuesto, argumentando que si el Tribunal declaraba inadmisible la apelación, la resolución de los demás asuntos planteados ante el Tribunal carecería de todo propósito debido al impacto de las utilidades excesivas en el monto de la indemnización ${ }^{32}$. La decisión del Tribunal fue que el Decreto del Presidente era un acto politico o un acto de gobierno, que no era susceptible de revisión.

En su opinión disidente, el Presidente de la Corte Suprema, Enrique Urrutia Manzano, favoreció la admisibilidad de la apelación de las compañías del cobre. Argumentó que la reforma constitucional confería jurisdicción al Tribunal para revisar "tanto la determinación de la indemnización como la disminución por rentas excesivas"33 y que esta era la única manera en que las compañías del cobre podían dar cumplimiento a la obligación de agotar la jurisdicción nacional que prevé la Resolución 1803. Sobre el particular declaró que "habría sido meramente ilusoria la creación de este Tribunal para sólo conocer del reclamo sobre las indemnizaciones fijadas, si al mismo tiempo a los afectados se les negaba el derecho de reclamar ante él, de la decisión sobre utilidades excesivas..."34. Agregó que el efecto de la decisión de la mayoría sería

\footnotetext{
${ }^{30}$ García Amador, Cuarto informe cit., Nota 10 supra, p. 16, según reformulado en García Amador; op. cit., Nota 9 supra, p. 222.

${ }^{31}$ Decisión del Tribunal Especial del Cobre, del 11 de agosto de 1972, sobre las utilidades excesivas de las compañías nacionalizadas, Diario Oficial, № 28,332 , 19 de agosto de 1972.

${ }^{32}$ Resumen de opiniones en Ibid., p. I6.

satbid., p. 23:

a'Ibid., p. 24.
} 
negar "a dichas empresas toda posibilidad de obtener una revisión jurisdiccional sobre el aspecto o fase quizás más importante"35, esto es, la determinación de las utilidades excesivas y su rebaja.

La decisión de la mayoría del Tribunal.se basó en gran medida en la teoría de que la determinación de las utilidades excesivas era una cuestión separada y distinta de la indemnización ${ }^{36}$. De acuerdo al párrafo 4 de la Resolución 1803 (XVII), que dispone que "En cualquier caso en que la cuestión de la indemnización" dé origen a un litigio debe agotarse la jurisdicción nacional, resulta claro que la jurisdicción nacional debe permanecer abierta para todos Ios efectos a los recurrentes extranjeros ${ }^{37}$. La aplicación de los principios del abuso del derecho y de la buena fe también llevaría a la misma conclusión. Más todavía, en el contexto de la nacionalización puede afirmarse que la cuestión de las utilidades excesivas es inseparable del problema de la indemnización.

\section{IV}

EL PUNTO DE VISTA DE LA DISCRIMINAGIÓN

Independientemente del debate doctrinario de si acaso los extranjeros deben ser tratados de acuerdo a condiciones más favorables que los nacionales en las controversias sobre afectación de propiedad, el derecho internacional exige que el Estado no discrimine entre nacionales y extranjeros en perjuicio de estos últimos ${ }^{38}$. En la opinión del gobierno de Chile este es el único requisito que el derecho internacional impone al Estado que adopta medidas de nacionalización en el interés nacional. ${ }^{39}$

Dos aspectos básicos de este problema fueron bien definidos er la presentación del Reino Unido en el-caso de la Anglo-Iranian Oil Co.:

35Ibid., p. 24.

${ }^{38}$ Ibid., pp. 18, 22.

${ }^{37}$ Doctrina y decisiones en Garcia Amador, Primer Informe sobre la responsabilidad internacional, Anuario de la Comisión de Derecho Internacional, Vol. II, 1956, pp. 204-206.

${ }^{38}$ Ibid., pp. 220-222.

${ }^{32}$ Véase Respuesta de la Delegación de Chile a la réplica del representante de los Estados Unidos, OEA, Doc. AG/C-145/72, 1972, pp. 1-2. Véase también la intervención del Ministro de Relaciones Exteriores cit., Nota 5 supra, p. 13. 
"El Gobierno del Reino Unido no niega... que pueden presentarse casos en que una medida de expropiación que afecte únicamente a extranjeros [esto es que afecte solamente a extranjeros porque sólo hay una empresa del tipo en cuestión y ella. es de la propiedad de extranjeros] obedezca a tan imperiosas consideraciones de utilidad pública y bienestar general que no pueda decirse que la medida se dirige o discrimina en contra de los extranjeros. En tales casos el hecho de que la expropiación afecta únicamente a extranjeros es, en cierto sentido, accidental. No puede esperarse que el Estado se abstenga de adoptar una medida que es de vital importancia por la sola razón de que las personas afectadas sean extranjeras... En cambio, la situación es enteramente diferente cuando hay clara evidencia de que la medida obedeció a sentimientos de resentimiento, animosidad o venganza en contra del extranjero en cuestión". ${ }^{40}$

La primera situación mencionada en esta presentación es claramente aplicable al caso de Chile. El propósito de las disposiciones constitucionales fue nacionalizar la industria del cobre, independientemente de toda consideración relativa a la nacionalidad de los propietarios afectados. No hubo por tanto discriminación. En lo que se refiere al segundo aspecto, el Presidente de la República ha asegurado repetidamente de que no hay venganza involucrada en. contra de los nacionales americanos cuyos intereses fueron afectados. ${ }^{41}$

No obstante lo anterior, el confuso y nuevo enfoque jurídico que resulta de la reforma constitucional, ofrece dificultades conceptuales desde este punto de vista. Durante la discusión en el Senado, quedó claramente establecido que las medidas de nacionalización afectarían a las "empresas" del cobre 42 , esto es, aquellas entidades en que tanto las compañías americanas como el Gobierno de Chile participaban. conjuntamente en virtud de los acuerdos alcanzados con la anterior administración. La idea de nacionalizar sólo las acciones de propiedad americana en las empresas fue expresamente re-

\footnotetext{
${ }^{40}$ Anglo-Iranian Oil Co. case: Memorial of the United Kingdom. En Whiteman: Digest of International Law, Vol. 8, 1967, p. 1055.

${ }^{42}$ Mensaje presidencial del 21 de diciembre de 1970 cit., Nota 1 supra, p. 15. Véase también el Discurso del Presidente sobre la nacionalización del cobre, La Nación, 22 de diciembre de 1970.

${ }^{42}$ Declaración presentada por el Presidente del Consejo de Defensa del Estado en el caso Braden Copper Company v. Administrative Commission, Corporación del Cobre, Empresa Nacional de Minería y John Doe (72 Civ. 508), febrero de
1972 , p. 3.
} 
Francisco Orrego T. / Problemas de derecho inter. por la nacionalización del cobre en Chile chazada, porque tal medida, se argumentó, habría sido discriminatoria. 43

La reforma constitucional que autorizó la nacionalización, declaró que los pagarés emitidos para la compra por Chile del $51 \%$ del capital de las compañias del cobre bajo los acuerdos anteriores de "chilenización", quedaban sin efecto y ordenó que todos los pagos que debieran realizarse por este concepto se descontaran de la indemnización. De esta manera, la inversión realizada por Chile se recuperaba in toto y en forma inmediata, que no era el caso de la inversión realizada por las compañías americanas. Es un hecho, sin embargo, que los intereses chilenos "afectados" por la nacionalización son en definitiva aquellos del Estado. El derecho internacional normalmente se preocupa de la discriminación que tiene lugar entre extranjeros y los nacionales del Estado que adopta, las medidas, pero, debido al enfoque jurídico que se siguió en este caso, se dio la situación en que el interés nacional "afectado" era el del propio Estado. Si este análisis es correcto, habria bastado con nacionalizar las acciones de propiedad americana, en lugar de nacionalizar la "empresa", pues el resultado habría sido el mismo en cualquier caso, esto es, el interés de Chile habría permanecido inafectado. Demás está decir que este último es el resultado normal de una nacionalización que no involucra los intereses de nacionales, pero aparentemente ello no fue percibido durante la discusión de la reforma constitucional.

\author{
V \\ EXPROPIACIÓN Y NACIONALIZAGIÓN
}

La idea de que la expropiación y la nacionalización son instituciones diferentes del derecho internacional fue expresada en todas las etapas de la discusión parlamentaria sobre la reforma constitucional ${ }^{44}$. En particular, se destacó que la nacionalización otorgaba ma-

\footnotetext{
"Declaración deI representante del Ejecutivo ante la Comisión del Senado, del 29 de diciembre de 1970 y del 11 de enero de 1971, Senado, Boletín cit., Nota 1 supra, pp. 37, 203. El peligro de la aplicación de la Enmienda Hickenlooper fue mencionado en este contexto.

${ }^{14}$ Senado, Boletín cit., Nota I supra, pp. 31-32, 89-91, 267-268, 278-279; también sesión del Senado, No 25, del 19 de enero de 1971; sesión No 26, del 20 de enero de 1971; y șesión $N$ is 31, del 2 de febrero de 1971. Actas publicadas en El Mercurio del $23 \mathrm{y}^{\prime} 26$ de enero y del 5 de febrero de 1971.
} 
yores poderes discrecionales al Estado ${ }^{45}$. EI proyecto original presentado por el Ejecutivo se refería a la "nacionalización por expropiación"46, lo que aparentemente revela que la distinción no fue considerada de gran importancia al comienzo del proceso. Sin embargo, la reforma fue posteriormente modificada para referirse sólo a la "nacionalización" a solicitud del representante del Ejecutivo, quien. indicó la necesidad de otorgar al Estado mayores poderes discrecionales ${ }^{47}$. Expresamente se señaló que esta distinción correspondía a una visión moderna del derecho internacional y en apoyo de esta posición se invocaron citas parciales de Katzarov y Schwarzenberger. ${ }^{48}$

No obstante, la doctrina del derecho internacional no está de " cuerdo acerca de la distinción jurídica entre "expropiación" y "nacionalización". Para algunos, la nacionalización afecta en forma impersonal masas universales de bienes en gran escala y en función de cambios operados en la estructura económico-social del Estado; la expropiación, en cambio, sólo afecta los derechos o propiedad de individuos. Las condiciones de la indemnización serían también diferentes en los dos $\operatorname{casos}^{49}$. En cierta medida esta fue la posición tomada por el Relator Especial de la Comisión de Derecho Internacional, particularmente en lo que se refiere a las condiciones de la indemnización, que serían más flexibles en el caso de las nacionalizaciones según lo revela la práctica de los "lumpsum agreements". Pero en su opinión, aparte de estas diferencias, "sustancialmente se trata de la misma institución jurídica, al menos desde el punto de vista del derecho internacional" 50 . Sin embargo, para otros autores, la nacionalización no tiene un significado jurídico propio en

\footnotetext{
${ }^{45}$ Senado, Boletín cit., Nota 1 supra, p. 32. Véase también Eduardo Novoa Monreal: La Batalla por el Cobre, 1972, pp. 107 172.

${ }^{10}$ Una expresión idéntica fue utilizada por la ley cubana sobre nacionalizaciones, NQ 851, del 6 de julio de 1960. En Whiteman: Digest of International Law, Vol. 8, 1967, p. 1042.

"Senado, Boletín cit., Nota I supra, pp. 282, 306. Varios senadores entendieron, sin embargo, que éste era sólo un problema terminológico y no de conceptos. Debate en la sesión del Senado, No 31, del 2 de febrero de 1971, publicada en El Mercurio del 5 de febrero de 1971.

${ }^{48}$ Senado, Boletín cit., Nota I supra, pp. 91, 267.

${ }^{40} \mathrm{~K}$. Katzarov: Teoría de la Nacionalización, 1963, pp. 264 et seq. Cuando explicó el proyecto de reforma constitucional propuesto por el gobierno, el representante del Ejecutivo indicó que la nacionalización afectaba la propiedad de la industria del cobre pero no a las empresas o sociedades. Senado, Boletin cit., pp. 204, 278. Posteriormente se indicó que las medidas afectaban a las empresas y a las sociedades mixtas, Ibid., p. 128 . Véase también la Nota 42 supra,
y Novoa, op cit., Nota 45 supra, pp. $172-197$.

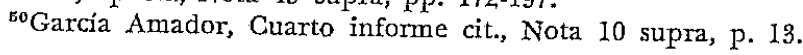


Prancisco Orrego T. / Problemas de derecho inter. por la nacionalizacion del cobre en Chile

el derecho internacional51, ni implica necesariamente el reconocimiento o la creación de un nuevo derecho. ${ }^{52}$

Desde el punto de vista de la Resolución 1803 (XVII), todas las medidas, cualquiera sea su clasificación, que afecten derechos adquiridos, no deben incurrir en arbitrariedad. El proyecto original presentado por Chile en la Comisión sobre Soberanía Permanente sobre Recursos Naturales, incluía una disposición muy similar al párrafo 4 de la Resolución $1803^{53}$, destinada a prevenir cualquier forma de arbitrariedad y a asegurar que las medidas adoptadas se basaran en principios previstos por el derecho54. Esta propuesta fue objeto de oposición de dos tipos. Por una parte, el Reino Unido favoreció restringir las medidas de afectación a aquellos casos en que fueran estrictamente requeridas por el interés nacional ${ }^{55}$. Por otra parte, la Unión Soviética se opuso al proyecto chileno porque no reconocía el derecho inalienable de los pueblos a nacionalizar y expropiar"5 "sin limitación alguna" 57 . Todas las modificaciones propuestas por la Unión Soviética en este sentido fueron rechazadas y Chile votó en contra de ellas en cada caso58. De ahí que el significado de la Resolución 1803 (XVII) sea que las medidas adoptadas por el Estado, ya sea por vía de expropiación, nacionalización u otra forma de afectación, deben conformarse a las condiciones exigidas por el derecho internacional.

\footnotetext{
${ }^{51}$ Wortley opina que "Nationaization is not a term of art". B. A. Wortley: Expropriation in Public International Law, 1959, p. 36.

${ }^{52}$ Katzarov, op. cit., Nota 49 supra, pp. 566-567.

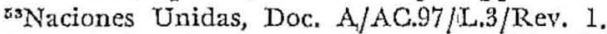

${ }^{5}$ Las declaraciones del delegado de Chile figuran en Naciones Unidas, Doc. A/C.2/SR.834, pp. 20-21 y A/AC.97//SR.25, p. 12. La referencia al derecho internacional que hace la Resolución 1803 fue incorporada con el propósito específico de llenar el vacío que en este sentido tenía la Resolución 626 (VII) del 12 de diciembre de 1952. Sobre este último punto véase Hyde: "Permanent Sovereignty over Natural Wealth and Resources", American Journal of International Law, Vol. 50, 1956, pp. 854-867.

${ }^{5}$ Naciones Unidas, Doc. A/C.2/L.669.

seIbid., A/AC.97/SR.32, pp. 7-8.

${ }^{57}$ Ibid., A/AC.97/L.2/Rev.1. Propuestas similares fueron presentadas en la segunda comisión de la Asamblea General. Véase Gess, loc. cit., Nota 3 supra, pp. $422-423$.

58Ibid., pp. 420-424.
} 
EL PROBLEMA DE LA INDEMNIZACIÓN

La obligación de pagar una indemnización por la afectación de la propiedad de un extranjero es un principio bien establecido del derecho internacional consuetudinario ${ }^{59}$. Esta obligación ha sido contemplada en el derecho interno de la mayoría de los paises ${ }^{60}$ y ha sido reconocida en la práctica incluso por los Estados socialistas. ${ }^{61}$

El significado de la Resolución 1803 (XVIX) en este aspecto es también claro. El proyecto de Resolución de Chile fue objeto de oposición de parte de la Unión Soviética, sobre la base de que al incluir la exigencia de la indemnización restringía la soberanía del pueblo $^{62}$, lo que explica que ninguno de los proyectos soviéticos contuviera disposiciones sobre indemnización. Según se observó anteriormente, todos estos proyectos soviéticos fueron rechazados. Otra enmienda propuesta por la Unión Soviética, que disponía que "La cuestión del pago de la indemnización a los dueños se decidirá en estos casos con arreglo a la legislación nacional del país que adopte esas medidas..."63, fue también rechazada, votando Chile por el rechazo. ${ }^{64}$

Defendiendo su propio proyecto, el delegado de Chile declaró:

"El proyecto de resolución añade la mención de una justa compensación cuando se adopta una medida de esta clase, lo mismo si el dueño es nacional del país que si es extranjero... Las ideas expuestas... Ilevaron a la conclusión de que era imposible una fórmula de transacción si se abandonaba la idea de la indemnización". ${ }^{65}$

${ }^{5}$ García Amador, Cuarto Informe cit., Nota 10 supra, p. 18.

${ }^{\circ}$ Katzarov, Op. cit., Nota 49 supra, p. 524.

"Drucker: "Compensation treaties between communist states", International and Comparative Law Quarterly, Vol. 10, 1961, p. 238. En todos los casos de nacionalizaciones europeas de la postguerra se contemplaron disposiciones para el pago de indemnización; García Amador, Cuarto informe cit., Nota 10 supra, p. 21.

${ }^{62}$ Naciones Unidas, Doc. cit., Nota 56 supra, pp. 7-8.

esibid., Doc. A/C.2/L.670.

"También Afganistán presentó una enmienda proponiendo que la indemnización se daria "cuando y donde resulte adecuada" (Naciones Unic̀as, Doc. A/C.2/ L.655), explicando que de otra manera se pondría en peligro la economía del pais y del mundo en su conjunto (Naciones Unidas, Doc. A/C.2//SR.834, p. 11).

${ }^{\circ}$ Naciones Unidas, Doc. A/G.2/SR.834. 
Con anterioridad había señalado que en el caso de medidas extremas, como la nacionalización, debía otorgarse una suma suficiente de compensación para asegurar que los derechos de los inversionistas fueran respetados. ${ }^{66}$

La reforma constitucional que autorizó la nacionalización del cobre estableció un mecanismo para la determinación de la indemnización y el avalúo de los bienes de las empresas afectadas. También numerosas declaraciones del Gobierno de Chile no niegan, como cuestión de principio, que la indemnización es procedente ${ }^{67}$. Sin embargo, el derecho internacional se preocupa no solamente de la obligación de indemnizar sino también de los requisitos y condiciones de su pago. Este último aspecto ha provocado una considerable controversia en el caso de las nacionalizaciones chilenas. El Gobierno de los Estados Unidos ha reafirmado en esta materia su posición tradicional de que, en virtud de los principios generalmente aceptados del derecho internacional, el Estado que afecta la propiedad de extranjeros debe proveer el pago de una "indemnización pronta, adecuada y efectiva"6s. Por otra parte, el Gobierno de Chile ha insistido que la cuestión de la indemnización se rige enteramente por los criterios establecidos en el derecho interno y que el derecho internacional no impone otra condición que la obligación de no discriminar en contra de los extranjeros. ${ }^{69}$

Estas posiciones conflictivas han dividido por muchos años a la comunidad académica y fueron la base misma de la discusión en torno a la Resolución 1803 (XVII). Si bien en la opinión de varios autores, la Resolución apoya la posición de los Estados Unidos ${ }^{70}$, esta no es la conclusión que deriva de su historia legislativa; tampoco la posición del Gobierno de Chile está enteramente de acuerdo con el significado de esta resolución. El hecho de que la

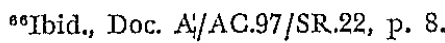

${ }^{\circ}$ Respuesta de la Delegación de Chile cit., Nota 39 supsa, pp. 1-2. Véase también Declaración del Ministro de Minería ante el Senado, Sesion No 25, 19 de enero de 1971; El Mercurio, 23 de enero de 1971, p. 8.

${ }^{\circ}$ Declaración de Charles A. Meyer cit., Nota 8 supra, p. 498. Sin embargo, la Declaración del Secretario de Estado del 13 de octubre de 1971 se refirió a una "disposición razonable para el pago de una indemnización justa". Department of State Bulletin, Vol. 65, 1971, p. 478. Para un examen de los principios aplicables de derecho internacional, interpretados en apoyo de esta posición, véase "An Analysis of the Expropriation of the Properties of Sociedad Ninera El Teniente by Chile in Light of International Law Principles". En R. Lillich (ed.), op. cit, Nota 29 supra, pp. 55-86.

${ }^{80}$ Respuesta de la Delegación de Chile cit., Nota 39 supra, p. 2. Véase también la Declaración del Ministro de Relaciones Exteriores cit., Nota 5 supra, p. 13. Ambas declaraciones indican que éste es el significado de la Resolución 1803.

${ }^{70} \mathrm{Gess}$, loc. cit., Nota 3 supra, pp. 427-428. Schwebel, loc. cit., Nota 3 supra, pp. $465 \cdot 466$. 
resolución se refiera tanto al derecho iñterno como al derecho internacional, indica que ambos ordenamientos jurídicos tienen una función relevante en esta materia.

A lo largo de los debates, la Delegación de los Estados Unidos argumentó que "indemnizáción correspondiente" sólo podía significar "indemnización pronta, adecuada y efectiva", proponiendo una enmienda en este sentido ${ }^{\text {t1. }}$. Según se indicó anteriormente, el punto de vista opuesto fue sostenido por la Unión Soviética y Afganistán, cuyas enmiendas o bien no mencionaron la cuestión de la indemnización o bien sujetaron su determinación exclusivamente a lo dispuesto por el derecho interno. Los siguientes comentarios formuládos por la Delegación de Chile acerca de estas posiciones, claramente revelan el sentido de equilibrio en que se inspira la Resolución 1803 (XVII) :

"El proyecto de resolución añade la mención de una justa compensación... Se han apuntado tres clases de ideas. Las primeras hacen figurar en el proyecto de resolución detalles que están fuera de lugar. Otras, al vincular la indemnización con su carácter adecuado, tienden a restringir las posibilidades de indemnización. Por último, la delegación de la Unión Soviética desea culminar la mención del derecho internacional en relación con la nacionalización... Para concluir, el orador cree que pocas veces una Comisión de la Asamblea General de las Naciones Unidas ha llegado a hacer un trabajo más cuidadoso concediendo una libertad completa para todás las tendencias. EI resultado es un texto equilibrado entre conceptos diferentes y conviene no romper ese equilibrio". 72

En orden a facilitar una transacción y tomando en consideración las declaraciones del Delegado de Chile en el sentido de que el proyecto no modificaba los principios existentes del derecho internacional, tanto los Estados Unidos como Afganistán retiraron sus respectivas enmiendas. Aquellas de la Unión Soviética fueron rechazadas. Por tanto es posible concluir que las exigencias y condiciones de la indemnización, dentro del significado de la Resolución 1803, definitivamente son reguladas por el derecho internacional dentro de un marco de flexibilidad que, por una parte, hace me-

${ }^{71}$ Naciones Unidas, Doc. A/C.2/L.668. Declaraciones en Doc. A/C.2/SR.835, pp. $5,10$.

"Iabid., Doc. A/C.2/SR.834, pp. 21-22. Este punto de vista equilibrado de la Resolución 1803 es también el elemento básico que destacan algunas interpretaciones. Véase Friedmann, op. cit., Nota 22 supra, p. 138. Y Asamoah, op, cit., Nota 4 supra, p. 97. 
nos rígida la aplicación de las exigencias tradicionales $y$, por otra parte, precave todas las formas de arbitrariedad que pudiera resultar de la sola aplicación del derecho nacional.7.3

El grado de flexibilidad que debe guiar la determinación de la indemnización en un caso particular, es una cuestión problemática para los internacionalistas. La exigencia mínima se refiere solamente a que la indemnización sea "justa" o "adecuada", "equitativa" o "razonable"74. Esta caracterización no significa, sin embargo, que exista un criterio fijo o universalmente reconocido, sino quizás solamente que en la determinación de la indemnización deben tomarse en cuenta tanto los intereses de la parte afectada como aquellos de la comunidad. Principios tales que el enriquecimiento injusto, el abuso del derecho, la buena fe y otros factores relevantes deben traerse a relación en el proceso de determinar el monto de la indemnización en un caso dado. De la misma manera, tampoco puede sorprender que no exista un criterio generalmente reconocido para la valuación de la propiedad expropiada en el derecho internacional ${ }^{75}$. En efecto, el desacuerdo acerca de la selección de un determinado criterio de valuación es la base de muchas controversias sobre indemnización. Las reclamaciones formuladas en apoyo de la medida de indemnización requerida por el derecho internacional, van desde el valor óptimo de una empresa como "going concern" hasta el valor de libros, pasando por una amplia gama de criterios intermedios. ${ }^{76}$

En el caso de las nacionalizaciones chilenas, desde un comienzo el representante del Ejecutivo señaló claramente ante la Comisión del Senado que la indemnización no cubriría el valor total de la propiedad afectada sino que sería solamente una indemnización parcial $^{77}$. El precedente de las nacionalizaciones europeas de post-

${ }^{73}$ Para la opinión de la doctrina en este aspecto, véase García Amador, Primer informe cit., Nota 37 supra, p. 241. También Katzarov reconoce que los criterios de la indemnización se rigen por el derecho internacional. Op. cit., Nota 49 supra, p. 496.

"Para un examen de la práctica y de las decisiones, véase García Amador, Cuarto informe cit., Nota 10 suppra, pp. 19-20. Para un útil análisis acerca del opaco concepto de indemnización "pronta", "adecuada", "efectiva", "justa" y "apropiada", y la necesidad de definir los elementos y criterios de valuación, véase Baxter "Foreword" a la obra de R. Lillich (ed.) cit., Nota 29 supra.

70Weigel and Weston: "Valuation upon the Deprivation of Foreign Enterprise: A Policy - Oriented Approach to the Problem of Compensation Under International Law'. En R. Lillich (ed.), op. cit., Nota 29 supra, pp. 3-39. Véase también McCosker: "Boock values in Nationalization Settlements". En Ibid., pp. 36-51.

${ }^{70}$ Friedmann, loc. cit., Nota 24 supra, p. 132.

${ }^{77}$ Senado, Boletín cit., pp. 91-93, 268, 278-279, 310. 
guerra fue constantemente invocado en apoyo de esta posición 78 . Sin embargo también hubo declaraciones claras en el sentido de que una nacionalización sin indemnización era inconcebible ${ }^{79}$. El hecho de que se escogiera el valor de libros como el criterio básico de valuación, al cual debían hacérsele diversas rebajas, es indicativo de la intención de otorgar un monto restringido de indemnización. La aplicación de tal criterio no puede ser considerada contraria al derecho internacional, en la medida en que no sea arbitraria o carezca de razonabilidad. Pero este es un aspecto que no puede ser juzgado imparcialmente por las partes involucradas, puesto que cada una estará solamente interesada en que prevalezca su propio interés. ${ }^{80}$

El criterio del valor de libros ajustado, por sí mismo no es inferior a los requerimientos mínimos del derecho internacional y puede muy bien responder a las circunstancias particulares de un caso dado, dentro de un marco de flexibilidad. De la misma manera, el concepto de flexibilidad es aplicable a la prontitud del pago de la indemnización. El pago diferido dentro de un período de tiempo es una práctica reconocida en el derecho internacional cuando las condiciones económicas del país justifican este método de pago ${ }^{81}$. A este respecto, la disposición constitucional que prevé el pago de la indemnización en un período de treinta años no debiera encontrar dificultad alguna.

Además, el problema de un pago "efectivo" parece no presentarse en el caso de la reforma constitucional, puesto que el Ejecutivo indicó que la indemnización sería en moneda dura o en moneda local a su respectiva tasa de cambio. ${ }^{82}$

Hay, sin embargo, dos aspectos que han complicado seriamente la nacionalización chilena: la cuestión de las utilidades excesivas $y$ el cumplimiento de las obligaciones contractuales.

rsibid., pp. 91-93, 278-279. Porcentajes de indemnización desde el $0 \%$ hasta el $70 \%$ fueron mencionados en este contexto.

"Tbid., pp. 124, 132.

${ }^{80}$ Véase en general Friedmann, loc. cit., Nota 24 supra, p. 132.

${ }^{81}$ Véase Sohn and Baxter, Proyecto de convención cit., Nota 7 supra, Artículo 10, No 4. Véase también García Amador, Cuarto informe cit., Nota 10 supra, p. 24. ${ }^{82}$ Véase el Mensaje Presidencial del 21 de diciembre de 1970. En Senado, Boletín cit., p. 14 . 
LA FUNCIÓN DEL DEREGHO NACIONAL Y LA CUESTIÓN DE LAS UTILIDADES EXCESIVAS

La función del derecho nacional, dentro del significado de la Resolución 1803, es básicamente la de ajustar el marco provisto por el derecho internacional a las circunstancias particulares de un caso determinado. En materia de afectación de propiedad el derecho internacional no puede ser rígido, pues ello no se avendría con el propósito de justicia que se persigue. Sin embargo, el Estado debe actuar dentro de un límite precisamente definido, pues ninguna de las condiciones de flexibilidad debe entenderse "como un abandono del principio de la no discriminación entre nacionales y extranjeros en perjuicio de los segundos...; ni tampoco que ellas autorizan al Estado a fijar una compensacióón que, ya por su cuantía, ya por la oportunidad; o por la forma en que se efectúa el pago, convierten a la expropiación en una medida confiscatoria o en un verdadero despojo de la propiedad privada". 83

Esto es, quizás, el contexto apropiado en que debe examinarse el problema de la compatibilidad de las rebajas por utilidades excesivas con el concepto de flexibilidad en el derecho internacional. Es claro que la doctrina no mira con mucha simpatía ningún tipo de medidas retroactivas, pues en general estas medidas no son compatibles con el respeto por los derechos adquiridos. Más todavía, la autorización para medidas retroactivas no se encuentra en los términos expresos de la Resolución 1803. Por la misma razón que el derecho internacional no obliga a un Estado a pagar indemnización por la afectación de propiedad cuando los derechos de la parte afectada han sido adquiridos bajo un sistema de derecho interno que expresamente no exige ese pago o entrega la cuestión de la indemnización enteramente a la discreción del Estado ${ }^{84}$, la indemnización puede ser exigida como cuestión de derecho y buena fe cuando el derecho a la propiedad ha sido adquirido bajo una legislación que prevé el pago de indemnización en caso de afectación ${ }^{85}$.

${ }^{83}$ García Amador, Guarto Informe cit., Nota 10 supra, p. 24. Véase también el Artículo 9,2 del proyecto del 11 de diciembre de 1961 cit., Nota 7 supra.

${ }^{84}$ Garcia Amador, Cuarto Informe cit., Nota 10 supra, pp. 18-19.

${ }^{85}$ Véase el Artículo 9,1 del proyecto del 11 de diciembre de 1961 cit, Nota 7 supra. 
Las utilidades legalmente obtenidas bajo la legislación en vigor son, desde luego, parte del derecho adquirido.

Aun asumiendo que el Estado tiene amplios poderes discrecionales en el caso de una nacionalización ${ }^{86}$, la cuestión de las utilidades excesivas siempre sería inseparable de la cuestión de la indemnización, puesto que la reforma constitucional previó su rebaja del monto de la indemnización. Ello además resulta implícito de la historia legislativa de esta reforma y de la resolución del Contralor General, quien, al rebajar las utilidades excesivas, resolvió que "no corresponde pagar indemnización" a algunas de las compañías del cobre $^{87}$. Podría argumentarse que la distinción hecha por el Tribunal Especial entre rebajas por utilidades excesivas e indemnización no tiene importancia real desde el punto de vista del derecho internacional ${ }^{88}$, como tampoco el describir la rebaja como política ayuda a resolver el problema ${ }^{89}$. Consecuentemente, aun si la medida pudiera justificarse, si como consecuencia de su aplicación no se alcanza el criterio de una indemnización justa, adecuada, equitativa o razonable, puede argumentarse que el derecho nacional excedió los límites de la flexibilidad contemplados por el derecho internacional.

\section{VIII}

LA CUESTIÓN DE LOS DERECHOS CONTRAGTUAIES

La nacionalización del cobre en Chile también ha estimulado las complejas discusiones doctrinarias acerca del cumplimiento de las obligaciones contractuales ${ }^{\ominus 0}$. En conformidad a la observación hecha por el relator especial de la Comisión de Derecho Internacional en el sentido de que el incumplimiento de un contrato sólo puede ser considerado per se contrario al derecho internacional cuando el con-

\footnotetext{
${ }^{88}$ García Amador distingue en este aspecto entre el caso de expropiación y el de nacionalización. Compárense los Artículos 9,1 y 9,2 del proyecto del il de diciembre de 1961 cit., Nota 7 supra. de 1971.

${ }^{8 T R e s o l u c i o ́ n ~ d e l ~ C o n t r a l o r ~ G e n e r a l ~ s o b r e ~ i n d e m n i z a c i o ́ n ~ d e l ~ I l ~ d e ~ o c t u b r e ~}$

${ }^{88}$ Véase Nota 36 supra.

${ }^{89}$ Declaración del representante del Ejecutivo ante la Comisión del Senado, en la sesión del 29 de diciembre de 1970, Senado, Beletín cit., p. 47.

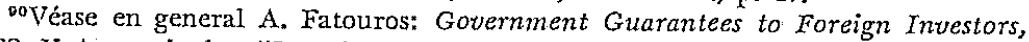
1962. Y Amerasinghe: "State Breaches of Contracts with Aliens and International Law", American Journal of International Law, Vol. 58, 1964, pp. 881:913.
} 
trato mismo es regido por el derecho internacional o por un sistema jurídico otro que el derecho interno de un determinado país ${ }^{91}$, los acuerdos. sobre "chilenización" no parecen quedar incluidos en esta categoria. Estos acuerdos se regían por el derecho interno y podían ser afectados por medidas de nacionalización sin comprometer la responsabilidad del Estado, siempre que se observaran las condiciones exigidas por el derecho internacional respecto de la arbitrariedad, discriminación, indemnización y otros principios relevantes. Las limitaciones impuestas por el derecho internacional sobre el funcionamiento del derecho interno, también son aplicables en esta materia.

EI mensaje presidencial con que se acompañó el proyecto de reforma constitucional al Congreso indicó claramente que uno de los propósitos de la nacionalización era el de afectar los contratos con las compañías del cobre, indicando también que se pagaría indemnización por los intereses afectados ${ }^{92}$. Sin embargo, durante la discusión en el Congreso, el representante del Ejecutivo señaló que no coincidía enteramente con esta posición pues, en su opinión, los contratos no eran válidos de acuerdo a la legislación en vigor al momento de su celebración y, por tanto, no debía pagarse indemnización en ningún caso ${ }^{93}$. No obstante, la opinión de la mayoría del Congreso fue que debía pagarse indemnización ${ }^{04}$. Esta determinación no se basó, como algunos han sugerido, en la teoría de que la obligación de cumplir los contratos es análoga a la obligación de cumplir los tratados ${ }^{25}$. Una disposición permanente fue incorporada a la constitución para este efecto ${ }^{96}$; sin embargo, no resulta claro qué efecto tendrá esta disposición en el caso de la nacionalización del cobre.

El problema fundamental planteado por la nacionalización en el derecho internacional es nuevamente aquel de la retroactividad. El resultado normal de una nacionalización es el afectar- los derechos que emanan de los efectos futuros del contrato, que ya no podrán reclamarse. Este es el caso de la disposición constitucional que declaró nula la promesa de compraventa de acciones correspondientes al $49 \%$ que todavía era de propiedad de las compañias americanas. Sin embargo, el representante del Ejecutivo señaló ante la Comisión del Senado que la intención de la reforma constitu-

${ }^{81}$ García Amador, Cuarto informe cit., Nota 10 supra, pp. 31-32.

${ }^{92}$ Mensaje presidencial del 12 de diciembre de 1970. Senado, Boletín cit, p. 11 . ${ }^{83}$ Senado, Boletín cit., pp. 24, 285.

'Ibid., pp. 123-124, 132, 283.

${ }^{95}$ Ibid., p. 286.

${ }^{\circ}$ Véase la parte final del Artículo 10, NQ 10, de la Constitución, según reformado. 
cional tenía un alcance mucho más amplio, y concretamente que las partes debían retrotraerse a la posición que existía con anterioridad àl momento de la celebración de los contratos ${ }^{77}$. Esto explica la incorporación en la reforma de la disposición que exigía imputar en el monto de la indemnización que se acordase a las compañías americanas, todo pago hecho por Chile por la compra del $51 \%$ de las acciones de las sociedades mixtas ${ }^{88}$. Pero, aun asumiendo que las partes retornaran al status quo ante y también asumiendo que esto sea compatible con la Resolución 1803, podría argumentarse que en cualquier caso las partes afectadas podrían reclamar una indemnización por los derechos adquiridos bajo las concesiones que se encontraban en vigor antes de los acuerdos de chilenización que se alcanzaron con el gobierno de Frei en 1967 y 1969.

Desde este punto de vista, el único efecto de la retroactividad sería el de sustituir el valor del $51 \%$ de las acciones según fue fijado por el acuerdo de chilenización, por el criterio del valor de libros ajustado.

IX

CONCLUSIÓN

La nacionalización de la industria del cobre plantea interrogantes significativos, y en muchos casos nuevos, acerca de lo que el derecho internacional exige o no exige en la afectación de propiedad que involucra los derechos de extranjeros. El hecho de que las partes en las controversias que emanan de nacionalizaciones hayan invocado prácticas y principios relevantes del derecho internacional en apoyo de sus respectivas posiciones, claramente indica la carencia de un consenso global acerca de los requerimientos del derecho internacional en materia de nacionalización de propiedad. Este ensayo ha procurado meramente destacar algunos de los problemas más controvertidos involucrados en una nacionalización. Cabe confiar en que los estudiosos y quienes ejercen el derecho internacional explorarán estos problemas en mayor profundidad en la medida en que vaya haciéndose disponible una mayor información. Las controversias provocadas por la nacionalización del cobre sólo podrán resolverse si acaso todas las partes interesadas trabajan conjuntamente en una atmósfera constructiva, con buena fe y mutua comprensión.

${ }^{97}$ Senado, Boletín cit., p. 310.

${ }^{98}$ Artículo transitorio 17 (h) de la Constitución, según reformado. 